\title{
APLICAÇÃO DO ULTRA-SOM EM SISTEMAS ELETROQUÍMICOS: CONSIDERAÇÕES TEÓRICAS E EXPERIMENTAIS
}

\author{
Gustavo S. Garbellini, Giancarlo R. Salazar-Banda e Luis A. Avaca* \\ Instituto de Química de São Carlos, Universidade de São Paulo, CP 780, 13560-970 São Carlos - SP, Brasil
}

Recebido em 24/8/06; aceito em 23/3/07; Publicado na web em 19/12/07

\begin{abstract}
ULTRASOUND APPLICATIONS IN ELECTROCHEMICAL SYSTEMS: THEORETICAL AND EXPERIMENTAL ASPECTS. The aim of this review is to present and discuss the applications of ultrasound in electrochemical systems such as in sonoelectroanalysis and sonoelectrolysis for the electrochemical combustion of organic compounds. Initially, theoretical and experimental aspects are discussed, particularly those related to the enhancement of mass transport and the surface cleaning effects. Some results are included to illustrate alternative geometries for the experimental measurements and the working electrodes used in these systems. In the sequence, the available publications are presented and discussed to demonstrate that ultrasound combined with electrochemical techniques is a powerful set-up for the detection of analytes such as metals and/or organic compounds in hostile media and for the effective destruction of toxic organic substances. At the end, a table summarizes the results already published in the literature.
\end{abstract}

Keywords: ultrasound; electroanalysis; electrolysis.

\section{INTRODUÇÃO}

Os benefícios do ultra-som em processos eletroquímicos têm sido bastante relatados e explorados na literatura ${ }^{1-5}$. Os trabalhos de revisão encontrados relatam aspectos teóricos do efeito do ultrasom em experimentos eletroquímicos e mostram a aplicação destes sistemas na análise de metais em água (eletrólito suporte) e em amostras complexas. Entretanto, nada foi relatado a respeito da detecção sonoeletroanalítica de compostos orgânicos, que apresentam uma forte interação com as diferentes superfícies eletródicas. Adicionalmente, outra questão que não tem sido considerada nestas revisões é a combustão eletroquímica de compostos orgânicos e subprodutos (produtos de degradação) utilizando a sonoeletroquímica.

Deste modo, justifica-se o interesse em entender e mostrar à comunidade científica, os efeitos do ultra-som nos processos eletroquímicos para o futuro desenvolvimento de metodologias de detecção e destruição de compostos tóxicos para a saúde humana e para o ambiente, considerando-se os trabalhos publicados nesta área de pesquisa até o momento.

A produção do ultra-som é um fenômeno físico baseado no processo de criar, aumentar e implodir cavidades de vapor e gases. Este processo é denominado cavitação, onde em um meio líquido, promove um efeito de ativação em reações químicas. Durante a etapa de compressão, a pressão é positiva, enquanto que a expansão resulta em vácuo chamado de pressão negativa, constituindose em um ciclo de compressão-expansão que gera as cavidades $^{6,7}$.

O ultra-som tem sido utilizado em sínteses orgânicas ${ }^{8}$, polimerização $0^{9,10}$, sonoluminescência ${ }^{11}$, sonólise ${ }^{12,13}$, preparação de catalisadores $^{6}$, sonoeletrosíntese ${ }^{14,15}$, entre outras aplicações, visando o entendimento da natureza da cavitação e dos efeitos químicos do ultra-som.

A aplicação do ultra-som a sistemas eletroquímicos caracteriza-se pela forte influência no transporte de massa até a interface eletrodo-solução ${ }^{1}$, em conjunto com efeitos benéficos tais como a limpeza da superfície eletródica ${ }^{16,17}$.

*e-mail: avaca@iqsc.usp.br
Os efeitos da aplicação do ultra-som no transporte de massa são complexos e têm sido propostos teoricamente ${ }^{18}$, empiricamente ${ }^{19-21}$ e por modelos aproximados de simulação ${ }^{22,23}$. Importantes aspectos da sonoeletroquímica foram relatados por Walter e Phull ${ }^{24}$ mostrando a quantificação de processos sonoeletroquímicos.

Em química o uso do poder do ultra-som pode ser dividido em duas principais áreas: processos homogêneos e heterogêneos. Os processos homogêneos podem ser induzidos por um colapso parcial ou total (cavitação) de pequenas bolhas ${ }^{6}$ que são acopladas a flutuações de pressão induzidas pelo ultra-som. Esses eventos de cavitação têm sido mostrados como uma fonte local de alta energia térmica, suficiente para uma clivagem homolítica de compostos presentes na, ou próximos à fase de vapor dentro da bolha. Espécies geradas sob estas condições como, por exemplo, radicais hidroxila ${ }^{25}$, halogêneos ${ }^{26}$ e outros radicais ${ }^{27}$ causam processos químicos nas proximidades das bolhas presentes na solução.

Os efeitos em processos heterogêneos incluem erosão de superfícies sólidas ${ }^{28}$ e uma mudança drástica no transporte de massa. A erosão é induzida por cavitação assimétrica ${ }^{29}$ próxima à interface eletrodo-solução e esse processo é responsável pela danificação e limpeza da superfície que, em alguns casos, mostra a presença de partículas ou filmes aderentes.

Os processos físicos relacionados ao transporte de massa como resultado de uma mistura do fluxo acústico e cavitação na eletroanálise são bem relatados na literatura ${ }^{30}$. O termo sonoeletroanálise ${ }^{2}$ é usado quando o ultra-som é aplicado a medidas eletroanalíticas. Metodologias sonoeletroanalíticas para análise de metais, como por exemplo, cádmio $^{31}$, apresentam limites de detecção na ordem de $10^{-11} \mathrm{~mol} \mathrm{~L}^{-1}$, utilizando técnicas voltamétricas de redissolução. Tais metodologias facilitam análises em matrizes complexas mediante efeitos de limpeza eletródica, por exemplo, de chumbo em vinho ${ }^{32}$ e de compostos orgânicos como a dopamina, em amostras de ovo ${ }^{33}$.

A combinação do ultra-som e a eletroquímica pode constituir uma solução interessante para os problemas atuais de tratamentos de águas residuárias, devido às dificuldades encontradas pelas técnicas convencionais como oxidação eletroquímica, aquecimento da água sob condições supercríticas e processos oxidativos. O poder do ultra-som pode melhorar a degradação eletroquímica de compostos 
por dois mecanismos: físico e químico ${ }^{34}$. Físico: a propagação de ondas acústicas em meios líquidos induz à cavitação, provocando o colapso violento a altas pressões acústicas. Entre os efeitos físicos desses colapsos estão as altas ordens de micromisturas e a limpeza das superfícies eletródicas por dissolução das camadas inibidoras, resultando principalmente na melhoria da transferência de massa sólido-líquido entre o eletrodo e a solução ${ }^{34}$. Químico: os efeitos químicos são também conseqüências dos colapsos violentos. A teoria do "hot spot" prediz temperaturas de milhares de kelvins e pressões de centenas de atmosferas dentro da bolha durante o final da compressão. Sob tais condições estáticas, espécies oxidadas são geradas pela clivagem homolítica das moléculas (gases e solvente). Em meios aquosos e na presença do oxigênio, os radicais assim formados podem melhorar consideravelmente o desempenho do processo eletroquímico para a destruição de resíduos perigosos ${ }^{34}$.

Portanto, nesta revisão, os efeitos do ultra-som na eletroanalítica e no tratamento de resíduos em águas contaminadas são discutidos. Para tais finalidades, são exploradas algumas considerações experimentais, aspectos teóricos a respeito do transporte de massa e do efeito do ultra-som na limpeza das superfícies eletródicas. Também são discutidos trabalhos relacionados à melhoria da sensibilidade em medidas eletroanalíticas e à degradação de compostos na presença do ultra-som.

\section{CONSIDERAÇÕES EXPERIMENTAIS}

Quando o ultra-som é aplicado a um sistema eletroquímico, parâmetros como a freqüência $(\mathrm{Hz})$, a intensidade $(\mathrm{W})$, o poder ultrasônico $\left(\mathrm{W} \mathrm{cm}^{-2}\right)$, determinado por calorimetria ${ }^{35}$, e a fonte de liberação do ultra-som devem ser considerados. Dentre esses, a freqüência, usualmente entre 20 e $800 \mathrm{KHz}$, não é o maior fator que modifica a intensidade de corrente de um processo redox. Entretanto, fontes ultra-sônicas de alta freqüência são conhecidas por produzirem uma maior quantidade de radicais hidroxila em meio aquoso em relação a fontes de baixas freqüências utilizando um mesmo poder ultra-sônico. As altas freqüências geralmente favorecem os mecanismos químicos envolvendo radicais (clivagem de ligações do substrato ou pela sonólise da água). Por outro lado, baixas frequiências são mais eficientes para efeitos mecânicos, como a eliminação de gases e a limpeza das superfícies eletródicas. O poder ultra-sônico é o parâmetro mais importante quando a radiação é aplicada a um sistema eletroquímico, pois há uma relação direta com o valor da corrente do processo redox ${ }^{36}$.

Diante dos trabalhos publicados na literatura a respeito da introdução do poder do ultra-som em uma célula eletroquímica, as duas maiores fontes de liberação do ultra-som encontradas foram os banhos ultra-sônicos e as sondas de imersão em forma de ponta.

O banho ultra-sônico (Figura 1a) consiste de um número de transdutores de frequiência fixa $(20-100 \mathrm{KHz})$ e tem a capacidade de limpar as superfícies e de ajudar a dissolução de substâncias ${ }^{1}$. O banho é preenchido com água destilada e a cela eletroquímica convencional é então colocada em uma posição fixa ${ }^{37}$. Neste arranjo, a cela é eletricamente separada e as ondas sonoras penetram na parede do material da cela (comumente vidro), antes de atingirem o reator eletroquímico convencional. Este tipo de fonte tem sido usado em reações de polimerização $0^{38}$, eletrodeposição de metais ${ }^{39,40}$ e em estudos mostrando a influência da intensidade do ultra-som aplicado na resposta sonoeletroquímica de alguns compostos ${ }^{36,41}$.

Por outro lado, estudos com o transdutor ultra-sônico em forma de ponta (Figura 1b) são bem mais freqüentes. Este consiste de uma unidade transdutora acoplada a uma ponteira inserida na cela eletroquímica. Em frente à ponteira há a formação de nuvens de bolhas cavitacionais a altas intensidades ${ }^{1}$. A ponteira mais utiliza- a
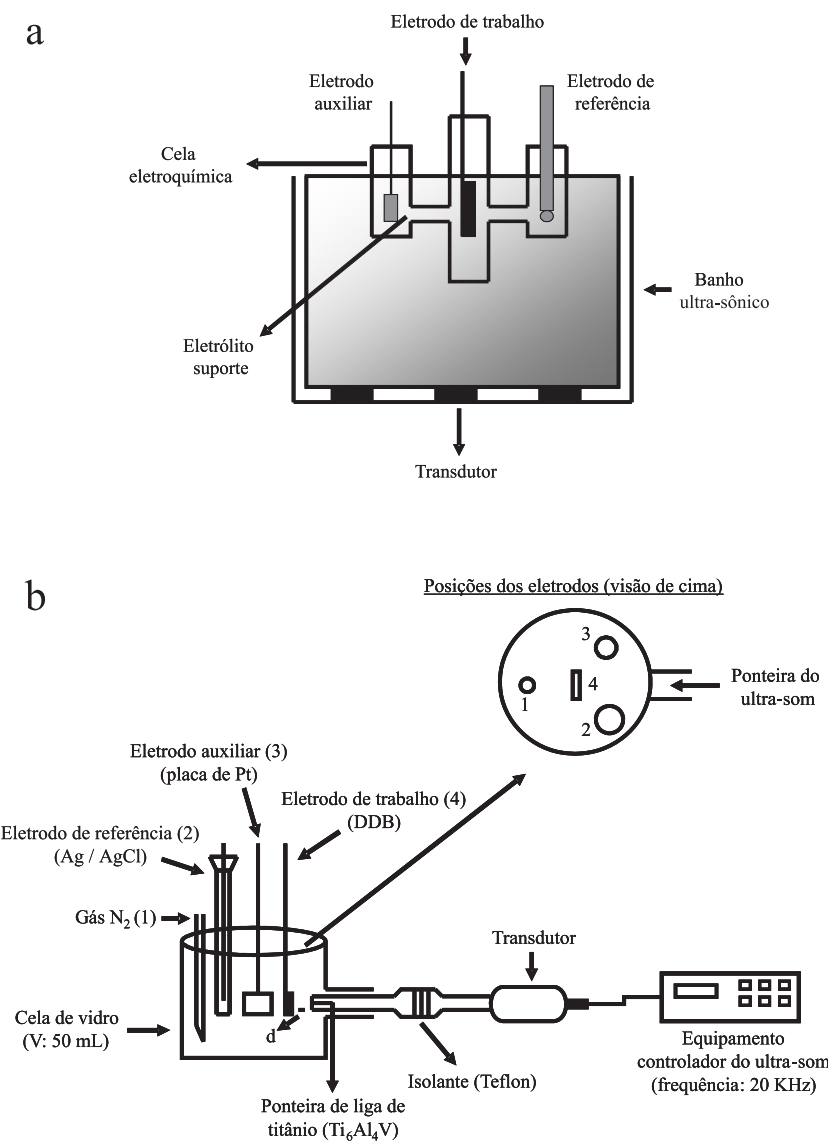

Figura 1. (a) Banho ultra-sônico contendo uma célula eletroquímica e (b) célula sonoeletroquímica em que a ponteira do ultra-som é localizada a uma distância $\mathbf{d}$ da superfície do eletrodo

da (liga de titânio: $\mathrm{Ti}_{6} \mathrm{Al}_{4} \mathrm{~V}$ ) deve ser considerada como uma parte ativa da cela. Nos trabalhos publicados pelo grupo do Prof. Compton (Universidade de Oxford), várias configurações ${ }^{42-46}$ foram utilizadas com sucesso para a determinação de diversos analitos, entre elas, quando o eletrodo de trabalho e a ponteira do ultra-som são colocados no mesmo ou em compartimentos diferentes na mesma cela eletroquímica.

A ponteira ultra-sônica apresenta uma série de vantagens ${ }^{1} \mathrm{em}$ relação ao banho ultra-sônico. Entre as principais podemos citar: a ponteira pode suportar altas intensidades de ultra-som (10-1000 W $\mathrm{cm}^{-2}$ ). Este poder diretamente aplicado ao sistema eletroquímico pode ser controlado pela amplitude da vibração da ponteira; a distância da ponteira ao eletrodo pode ser usada como parâmetro para controlar o poder do ultra-som em um sistema eletroquímico; a ponteira pode ser usada como um eletrodo; a geometria e as dimensões da cela eletroquímica têm um pequeno efeito sobre os processos eletródicos observados.

Mas este transdutor também tem limitações ${ }^{1}$, como a erosão da ponteira de liga de titânio que libera partículas de titânio no sistema químico de interesse e que pode causar uma contaminação; a dificuldade em manter a temperatura constante durante o experimento eletroquímico, devido ao efeito de aquecimento resultante da agitação da solução e a necessidade do controle bipotenciostático ${ }^{47}$, devido ao contato direto da ponteira do ultra-som com o sistema eletroquímico, ou seja, a liga de titânio apresenta um potencial em relação ao eletrodo de referência. Esse problema pode ser resolvido isolando o transdutor da ponteira, pela introdução de um disco de Teflon (Figura 1b).

Um trabalho pioneiro em nosso laboratório foi desenvolvido por Zanotto-Neto ${ }^{48}$ que descreveu a utilização do ultra-som em conjunto 
com diversas técnicas voltamétricas usando o eletrodo de diamante dopado com boro (DDB) para a determinação eletroanalítica do 4nitrofenol (4-NF) em águas puras e naturais (águas de rios). O limite de detecção (LD) medido para a oxidação do 4-NF usando a voltametria de onda quadrada (SWV), em uma frequiência de $10 \mathrm{~s}^{-1}$, assistido pelo ultra-som foi de $1,5 \mu \mathrm{g} \mathrm{L}^{-1}$, valor menor que o limite de detecção existente na literatura para experimentos similares, mas sem o ultrasom e usando uma freqüência de $100 \mathrm{~s}^{-1} 49$. Um arranjo para o acoplamento do ultra-som ao sistema eletroquímico, semelhante ao da Figura 1b, foi utilizado para as medidas sonoeletroanalíticas.

Os experimentos com o sistema da Figura 1b e também com outras configurações existentes podem ser conduzidos usando arranjos geométricos alternativos da ponteira em relação ao eletrodo de trabalho, sendo: (a) Geometria "Face on" ${ }^{50-53}$ : ponteira do ultrasom é colocada em frente ao eletrodo de trabalho; (b) geometria "Side-on" "54: o eletrodo de trabalho é colocado perpendicularmente à ponteira do ultra-som; (c) a ponteira do ultra-som pode ser usada como eletrodo de trabalho (Sonotrodo) ${ }^{55}$.

Um detalhe experimental importante está relacionado à dureza do material eletródico. Na presença do ultra-som, os eletrodos são expostos a condições extremas provocada por altas pressões e fluxos induzidos pela forte cavitação, suficientes para causar uma erosão nas superfícies. Compton e colaboradores ${ }^{50}$ mostraram que os eletrodos de platina e de alumínio são degradados após alguns minutos de exposição ao ultra-som. Em materiais como o carbono vítreo $^{56,57}$, nenhum dano foi detectado após um período de $30 \mathrm{~min}$ de aplicação da radiação. Por outro lado, esse tempo aplicado à superfície do ouro ${ }^{57}$, causou uma considerável rugosidade. Apesar disso, estes materiais podem ser usados em estudos sonoeletroquímicos, visto que estes danos dependem, por exemplo, da intensidade da radiação aplicada e também da distância entre o eletrodo e a ponteira de titânio. Uma alternativa viável para substituir os materiais baseados em carbono, tais como grafite e carbono vítreo, é o diamante, devido a sua extrema dureza e resistência à corrosão. Os eletrodos de DDB sob condições violentas não têm apresentado indícios de erosão ou destruição da superfície ${ }^{58,59}$. Exemplificando, a determinação de chumbo em sedimentos de rio sobre este eletrodo utilizando a voltametria de redissolução e o ultra-som foi realizada em um período total de $60 \mathrm{~min}$, sem a ocorrência de danos na superfície eletródica ${ }^{43}$, mostrando que o eletrodo de diamante pode ser considerado o material eletródico ideal para experimentos sonoeletroquímicos.

\section{INFLUÊNCIA NO TRANSPORTE DE MASSA}

O efeito no transporte de massa induzido pelo ultra-som é um importante aspecto da sonoeletroquímica ${ }^{60}$. A aplicação do ultrasom a uma solução pode aumentar drasticamente o transporte do material eletroativo à superfície eletródica. Muitos autores têm se dedicado a desenvolver descrições quantitativas e à identificação dos processos físicos envolvidos ${ }^{18,19,61-64}$. Na Figura 2a estão apresentados voltamogramas cíclicos típicos da reação do par reversível $\mathrm{Fe}(\mathrm{CN})_{6}^{4-/ 3-}$ sobre um eletrodo de DDB em meio de $\mathrm{KCl} 0,1 \mathrm{~mol}$ $\mathrm{L}^{-1}$ na ausência (I) e na presença do ultra-som (II).

$\mathrm{O}$ voltamograma da Figura $2 \mathrm{a}(\mathrm{I})$ apresenta uma resposta eletroquímica característica de um sistema reversível (par redox). A Figura 2a(II) mostra uma medida nas mesmas condições, na presença do ultra-som (amplitude: 30\%) direcionado à superfície do eletrodo de DDB, usando o arranjo experimental mostrado na Figura 1b, com uma separação da ponteira do ultra-som ao eletrodo de $10 \mathrm{~mm}$. A intensidade da corrente do voltamograma obtido na presença do ultra-som é significativamente maior se comparada à corrente obtida no voltamograma sem o uso do ultra-som. Além
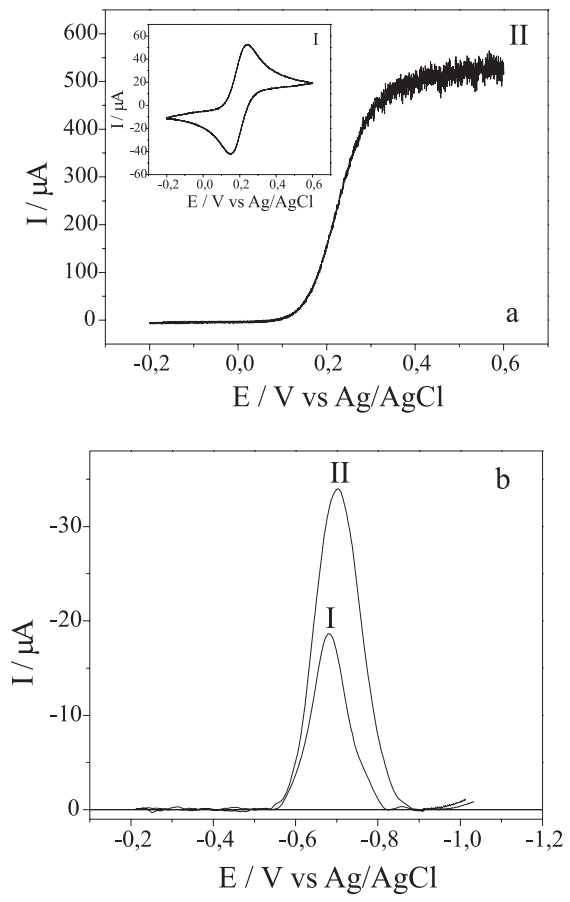

Figura 2. (a) Voltamogramas cíclicos obtidos para $1,0 \times 10^{-3} \mathrm{~mol} \mathrm{~L}^{-1}$ de $\mathrm{K}_{4}\left[\mathrm{Fe}(\mathrm{CN})_{6}\right] .3 \mathrm{H}_{2} \mathrm{O}$ em meio de $\mathrm{KCl} \mathrm{0,1} \mathrm{mol} \mathrm{L}^{-1}$ (v: $\left.50 \mathrm{mV} \mathrm{s}^{-1}\right)$ na ausência (I) e na presença do ultra-som, varreduras direta e reversa (II). (b) Voltamogramas de onda quadrada para a redução de $2,0 \times 10^{-5} \mathrm{~mol} \mathrm{~L}^{-1}$ de metilparation (Tampão BR 0,1 mol L $L^{-1}$ a pH 7,0; SWV: f: $150 \mathrm{~s}^{-1}$, a: $40 \mathrm{mV}$, $\Delta E s: 2 \mathrm{mV}$ ) na ausência (I) e na presença do ultra-som (II). Condições do ultra-som: $\mathrm{K}_{4}\left[\mathrm{Fe}(\mathrm{CN})_{6}\right] .3 \mathrm{H}_{2} \mathrm{O}$ : Amplitude de vibração da ponteira de $30 \%$ a uma distância ponteira-eletrodo de $10 \mathrm{~mm} /$ Metilparation: $20 \%$ a $5 \mathrm{~mm}$. Ambos estudos sobre um eletrodo de DDB (Ag: 0,25 $\left.\mathrm{cm}^{2}\right)$

disso, o perfil do voltamograma sem o ultra-som é modificado de um típico voltamograma cíclico, para um voltamograma com a forma sigmoidal, indicando que o constante transporte de massa de espécies eletroativas à superfície eletródica é sustentado pela corrente estacionária. A magnitude da corrente limite dos voltamogramas na presença do ultra-som para o ferrocianeto de potássio aumenta à medida que a distância da ponteira do ultra-som ao eletrodo diminui e, também, quando há um aumento na intensidade do ultra-som aplicado.

Um outro exemplo da melhora do transporte de massa na presença do ultra-som foi avaliado pela voltametria de onda quadrada ${ }^{65}$. Esta é uma das técnicas voltamétricas mais usadas no nosso grupo de pesquisa para o desenvolvimento de métodos eletroanalíticos para a detecção de compostos orgânicos ${ }^{49,66-68}$. Esta avaliação foi realizada para a determinação do pesticida metilparation, um composto altamente tóxico, que se adsorve na superfície do eletrodo de $\mathrm{DDB}^{69}$. A Figura $2 \mathrm{~b}$ mostra os voltamogramas de onda quadrada para a redução do composto sobre o eletrodo de DDB na ausência (Figura $2 \mathrm{bI}$ ) e na presença do ultra-som (Figura 2bII). Notou-se um aumento na intensidade de corrente do voltamograma na presença do ultrasom em relação ao voltamograma sem ultra-som, justificado pelo aumento do transporte de moléculas do metilparation.

Como visto, o ultra-som providencia um aumento no transporte de material eletroativo. Essa convecção forçada pode ser medida assumindo que a aplicação do ultra-som resulta numa diminuição da espessura da camada de difusão $(\delta)$. $O$ modelo da camada de difusão permite uma descrição do transporte de massa à interface do eletrodo considerando uma subcamada laminar próxima à superfície e um gradiente de concentração aproximadamente linear através de uma fina 
camada adjacente ao eletrodo. A Equação 1 descreve o transporte em um eletrodo submetido à radiação de ultra-som baseado no modelo eletródico "acessivelmente" uniforme (valor da $\delta$ constante sobre a superfície do eletrodo), sendo o eletrodo maior que o tamanho da $\delta^{1,3}$.

$I_{\lim }=\frac{n F D A C_{\text {seio }}}{\delta}$

onde $n$ é o número de elétrons transferido, $F$ é a constante de Faraday, $D$ o coeficiente de difusão, $A$ a área do eletrodo, $C$ a concentração no seio da solução e $\delta$ a espessura da camada de difusão.

Para processos sonoeletroquímicos, a análise das correntes baseadas no modelo da camada de difusão de Nernst permite critérios adicionais a respeito do processo de transporte de massa se espécies eletroativas com variados coeficientes de difusão são comparadas. A $\delta$ é uma função dos coeficientes de difusão, $\delta(D)=D^{x}$, onde o expoente $\mathrm{x}$ pode ser considerado um indicador da natureza do processo de transporte de massa ${ }^{70}$.

Experimentos conduzidos utilizando a geometria "face-on" mostraram que um eletrodo sob a presença do ultra-som se comporta como um eletrodo hidrodinâmico ${ }^{1,3}$. Nesses casos de difusão e convecção simultâneas, o gradual aumento na $\delta$ que ocorre com o aumento da distância entre a colisão do fluxo e a superfície leva a uma diminuição no fluxo difusional. Isto resulta em uma densidade de corrente não uniforme ao longo da superfície eletródica. É importante notar que a $\delta$ depende não somente de fatores hidrodinâmicos, mas também da natureza das espécies difusionais, por meio dos coeficientes de difusão, parâmetros que dependem da concentração e cujos valores diferem entre as várias substâncias ${ }^{71}$.

Além disso, a $\delta$ depende do poder do ultra-som aplicado e do raio do eletrodo. A $\delta$ é apreciavelmente menor para microeletrodos em relação a eletrodos de dimensões convencionais, embora, para ambos os casos, a $\delta$ na presença do ultra-som seja significativamente menor que aquela na ausência da radiação ${ }^{51}$. Vale ressaltar que eletrodos de dimensões na ordem de $\mu \mathrm{m}$ (entre 0,8 e 50,0 $\mu \mathrm{m}$ ) conhecidos como ultramicroeletrodos apresentam propriedades vantajosas em relação a eletrodos convencionais (maiores que 50,0 $\mu \mathrm{m}$ ). Suas dimensões são da mesma ordem que as da camada de difusão, implicando em uma alta velocidade no transporte de massa, devido à forma esférica da camada de difusão, o que facilita o estudo de reações eletródicas rápidas sob condições de estado estacionário, atingido em tempos muito mais curtos que com eletrodos convencionais $^{72}$.

A melhora do transporte é muito dependente da geometria da ponteira do ultra-som em relação à superfície eletródica. Uma aproximação do efeito do ultra-som no transporte de massa até a superfície do eletrodo é possível somente pela consideração do efeito do fluxo acústico e por tratamentos de sistemas similares em casos relatados na voltametria hidrodinâmica. O conhecimento em detalhes dos parâmetros que influenciam na melhora do transporte de massa em conjunto com o modelo previsto pela Equação 1 pode ser empregado para uma posterior análise individual dos efeitos físicos em certos arranjos experimentais (cela eletroquímica e fontes ultra-sônicas) que dependem do fluxo acústico, em relação aos efeitos químicos reais, como a detecção de radicais intermediários em estudos mecanísticos.

\section{LIMPEZA DAS SUPERFÍCIES ELETRÓDICAS POR CAVITAÇÃO}

O ultra-som, quando aplicado diretamente à superfície de eletrodos, pode causar uma severa degradação da superfície pela erosão do material eletródico ${ }^{50}$, assim como induzir a ativação e melhoria no desempenho devido à limpeza do eletrodo ${ }^{50,56}$. Estu- dos de mudanças que ocorrem nas superfícies eletródicas na presença do ultra-som devem ser acompanhados por alguma investigação eletroquímica para mostrar um quadro completo dos processos envolvidos ${ }^{1}$. A microscopia de força atômica (MFA) ${ }^{50,57}$ e a microscopia eletrônica de varredura $(\mathrm{MEV})^{56}$ podem ser usadas para a investigação de vários tipos de superfícies eletródicas.

O que causa a limpeza da superfície eletródica? Em uma análise de nitrito em ovos ${ }^{73}$, por exemplo, moléculas de proteínas e gorduras presentes nas amostras adsorvem-se na superfície, inativando o eletrodo. Estas moléculas são removidas pelo processo de cavitação $0^{30,74}$, efeito chave do processo de limpeza. Entretanto, poucas informações sobre os aspectos fundamentais deste processo são conhecidas.

A depassivação dos substratos eletródicos é de fundamental importância para a sonoeletroquímica, onde detecções eletroquímicas convencionais, por exemplo, por voltametria de redissolução anódica em um meio altamente passivador, falhariam. Em alguns casos, o poder do ultra-som transforma sinais invisíveis de espécies metálicas em sinais capazes de serem quantificados ${ }^{3}$. Exemplos dessa limpeza eletródica são mostrados na Figura 3 onde, para compostos como o carbaril (inseticida) e o 4-nitrofenol (proveniente da degradação de pesticidas organofosforados), sucessivas varreduras por SWV na ausência do ultra-som mostraram uma diminuição na resposta voltamétrica, justificada pelo bloqueio da superfície eletródica, devido à adsorção de produtos da oxidação de ambos os compostos. Já na presença do ultra-som, essas varreduras sucessivas apresentaram respostas semelhantes, mostrando que o ultra-som aplicado nestas condições é capaz de limpar a superfície eletródica. Adicionalmente, para os dois compostos, observou-se o aumento da intensidade de corrente do primeiro voltamograma obtido na presença do ultra-som, gerado pelo aumento do transporte de massa, se comparado ao pri-
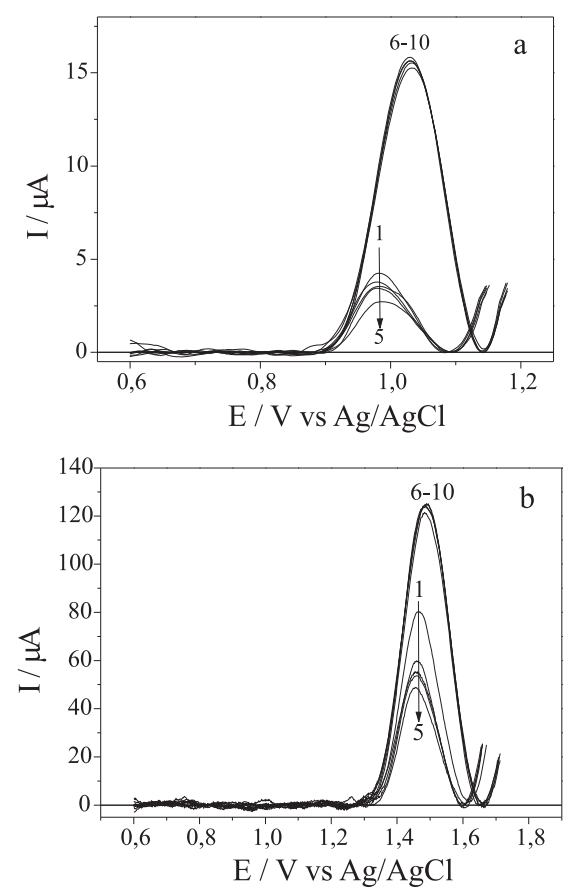

Figura 3. Sucessivos voltamogramas de onda quadrada sobre o eletrodo de DDB (Ag: 0,25 $\left.\mathrm{cm}^{2}\right)$ para a oxidação de: a) 4-nitrofenol (1,97 $\left.\times 10^{-5} \mathrm{~mol} \mathrm{~L}^{-1}\right)$ e b) carbaril (2,0 $\times 10^{-5} \mathrm{~mol} \mathrm{L^{-1 } )}$ na ausência (1-5) e na presença do ultrasom (6-10). Condições: (a) Tampão BR 0,1 mol L-1 a pH 6,0; SWV: $f: 100 \mathrm{~s}^{-1}$, a: $50 \mathrm{mV}, \Delta E s: 2 \mathrm{mV}$; (b) $\mathrm{Na}_{2} \mathrm{SO}_{4} 0,1 \mathrm{~mol} \mathrm{~L} \mathrm{~L}^{-1}$ a pH 6,0; SWV: f: $300 \mathrm{~s}^{-1}$, a: 50 mV, $\Delta$ Es: 2 mV. Ultra-som (a e b) : Amplitude de vibração da ponteira de $20 \%$ a uma distância ponteira-eletrodo de $5 \mathrm{~mm}$ 
meiro voltamograma na ausência da radiação.

A seguir são mostrados os trabalhos encontrados na literatura relativos à sonoeletroanálise de espécies metálicas e de alguns compostos orgânicos e à combustão eletroquímica de compostos orgânicos na presença do poder do ultra-som.

\section{APLICAÇÃO DO ULTRA-SOM NA ELETROANÁLISE}

A maioria dos trabalhos encontrados na literatura que se referem à eletroanálise mostra a determinação individual de metais ou de compostos orgânicos em diversas amostras, por técnicas clássicas (sem agitação da solução), tais como as voltamétricas. No entanto, cada uma dessas técnicas de análises "silenciosas" (sem o uso do ultra-som) é impedida pela falha/inativação do eletrodo que ocorre em aplicações analíticas não-ideais. Muitos meios analíticos encontrados externamente ao laboratório contêm materiais que podem passivar os eletrodos. Desta forma, uma monocamada de alguma substância cobrindo o eletrodo é suficiente para perturbar os processos eletródicos ${ }^{4}$. Por exemplo, a determinação eletroquímica de íons cobre na cerveja é impossível devido à passivação do eletrodo por espécies orgânicas adsorvidas. A análise de amostras contendo proteínas, polímeros solúveis, açúcares e plasma sangüíneo são também impedidas pelas mesmas razões de bloqueio do eletrodo ${ }^{4}$.

A ocorrência de passivação do eletrodo foi superada pelo HMDE (eletrodo de gota pendente de mercúrio) que permite a regeneração constante de uma nova superfície de mercúrio. Entretanto, o uso deste material em altas quantidades é extremamente indesejável, considerando sua toxicidade e usos restritos ${ }^{4}$. Além disso, este eletrodo não pode ser usado em processos oxidativos.

Características como a passivação do eletrodo, toxicidade do mercúrio e consumo de tempo para preparação das amostras são alguns dos principais fatores responsáveis pela baixa exploração das análises eletroquímicas por redissolução, como uma ferramenta analítica comum ${ }^{4}$

Uma alternativa para se superar os efeitos de passivação do eletrodo, permitindo uma análise eletroquímica sensitiva que possa ser realizada em meios "hostis", incluindo sangue, efluentes, alimentos e combustíveis, é a utilização do ultra-som4.

Como descrito anteriormente, a introdução do ultra-som em células voltamétricas tem um efeito marcante sob o transporte de massa e características de ativação da superfície do eletrodo em um sistema eletroquímico. O transporte de massa é aumentado via um fluxo acústico e microfluxos (microbolhas), resultando em um colapso cavitacional local para a superfície eletródica. Em adição, a ativação da superfície via erosão cavitacional pode ser usada com sucesso para ativar eletrodos passivados. O uso do ultra-som com técnicas eletroanalíticas oferece melhoras nas ordens de reações, tempo de análise, limites de detecção e tempo de vida do eletrodo, comparadas às condições alcançadas sem o uso do ultra-som ${ }^{4}$.

Vários trabalhos foram encontrados na literatura relatando o uso do ultra-som em determinações eletroanalíticas de metais utilizando técnicas de redissolução sobre diferentes tipos de eletrodo de trabalho e em diversas matrizes. Alguns destes trabalhos são detalhados a seguir, assim como aqueles de compostos orgânicos em diversas matrizes complexas.

\section{Cádmio}

Banks e colaboradores ${ }^{75}$ relataram a deposição e a detecção de cádmio usando o eletrodo de DDB, por meio da voltametria de redissolução anódica auxiliada pela SWV em água pura (eletrólito suporte). Obtiveram limites de detecção de $2,5 \times 10^{-8} \mathrm{~mol} \mathrm{dm}^{-3}$ na ausência do ultra-som e de $3,9 \times 10^{-9} \mathrm{~mol} \mathrm{dm}^{-3}$ na presença da radi- ação. A comparação com a deposição sem o ultra-som revela que o campo acústico melhorou o limite de detecção em um fator de 6 . Essa diminuição no limite de detecção, claramente evidente na presença do ultra-som, confirma os efeitos benéficos na melhora do regime de transporte de massa na deposição.

Kruusma e colaboradores ${ }^{76}$ utilizaram a sonovoltametria de redissolução anódica em conjunto com a SWV em meio emulsificado para a detecção de cádmio e zinco. O método foi aplicado para a detecção de zinco em shampoo comercial e pasta dentária, mostrando que o conjunto sono-extração bifásico e sonovoltametria, é uma técnica interessante para a detecção de cádmio e zinco em meios hostis (passivadores).

Em outro trabalho de Kruusma e colaboradores ${ }^{77}$, concentrações de cádmio foram determinadas por voltametria de redissolução anódica em sangue humano na presença do ultra-som. Os valores de concentração de cádmio obtidos foram comparados com valores obtidos por espectroscopia de absorção atômica, mostrando boa concordância.

\section{Chumbo}

Saterlay e colaboradores ${ }^{43}$ relataram o desenvolvimento de uma metodologia que usa a voltametria de redissolução catódica assistida com o ultra-som sobre o eletrodo de DDB para a detecção de chumbo em sedimentos de rio. A faixa do limite de detecção obtido foi de $10^{-8}$ a $10^{-7}$ mol L ${ }^{-1}$ utilizando a SWV. Já para a voltametria de varredura linear, os limites de detecção não foram relatados.

Akkermans e colaboradores ${ }^{32}$ utilizaram a voltametria de redissolução anódica para a detecção de chumbo em vinho, obtendo resultados satisfatórios, quando comparados a valores obtidos por espectroscopia de absorção atômica. Em outro trabalho, Akkermans e colaboradores ${ }^{78}$ utilizaram sonotrodos para a detecção de chumbo em soluções aquosas por voltametria de redissolução anódica. Neste caso, o mercúrio $\left(\mathrm{Hg}^{2+}\right)$ foi adicionado à solução para permitir a formação de amálgama chumbo/cobre na platina (proveniente da ponteira do ultra-som) do sonotrodo.

Blythe e colaboradores ${ }^{79}$ mostraram a detecção de chumbo em amostras de petróleo, empregando procedimentos de emulsificação, por meio da voltametria de redissolução anódica na presença do ultra-som. O elevado transporte de massa e os efeitos de limpeza eletródica (ativação da superfície) preveniram a inativação do eletrodo proveniente da adsorção de outros componentes do petróleo.

West e colaboradores ${ }^{42}$ mostraram a aplicabilidade da voltametria de redissolução anódica e onda quadrada acompanhada do ultra-som para a detecção de chumbo em amostras de saliva. Foi utilizado um eletrodo de disco de carbono vítreo e um eletrodo de carbono vítreo com filme fino de mercúrio recoberto com Nafion ${ }^{\circledR}$.

\section{Manganês}

Em trabalho publicado por Saterlay e colaboradores ${ }^{80}$, foi apresentada uma metodologia utilizando a voltametria de redissolução catódica assistida com o ultra-som, sobre o eletrodo de DDB, para a detecção de manganês em amostras de chá instantâneo. Obtiveram um limite de detecção na ordem de $10^{-11} \mathrm{~mol} \mathrm{~L}^{-1}$.

Goodwin e colaboradores ${ }^{81}$ monitoraram os níveis de manganês em águas de rio usando um eletrodo de DDB e a voltametria de redissolução catódica. Esta metodologia foi usada para avaliação de manganês em amostras de rio coletadas próximo a uma indústria produtora de ferromanganês, na Croácia.

\section{Arsênio}

Simm e colaboradores ${ }^{82}$ mostraram a detecção de arsênio via 
voltametria de redissolução anódica utilizando três eletrodos, sendo um de ouro, um de platina e outro de prata. O limite de detecção encontrado para a detecção de As(III) em um eletrodo de prata, por exemplo, foi de $6,3 \times 10^{-7} \mathrm{~mol} \mathrm{~L}^{-1}$. O uso do ultra-som em tais medidas eletroanalíticas melhorou o limite de detecção, diminuindo-o para $1,4 \times 10^{-8} \mathrm{~mol} \mathrm{~L}^{-1}$.

Estes mesmos autores ${ }^{83}$ realizaram também a detecção eletroanalítica de arsênio sobre um eletrodo de ouro na ausência e na presença do ultra-som. $\mathrm{Na}$ ausência da radiação, o limite de detecção obtido foi de $1,8 \times 10^{-7} \mathrm{~mol} \mathrm{~L}^{-1}$ usando um tempo de préconcentração de $120 \mathrm{~s}$. Aplicando o ultra-som durante a acumulação, o limite de detecção foi diminuído para $1 \times 10^{-8} \mathrm{~mol} \mathrm{~L}^{-1}$. A metodologia foi testada em amostras de águas de rio contendo significativas concentrações de cobre e materiais orgânicos capazes de inativar o eletrodo. Neste trabalho, foram observados os efeitos de limpeza eletródica devido à utilização do ultra-som.

\section{Prata}

Saterlay e colaboradores ${ }^{84}$ realizaram uma investigação sonoeletroquímica da detecção de prata em um eletrodo de DDB utilizando a voltametria de redissolução anódica e catódica. As medidas por voltametria de redissoluçao catódica, via eletrodeposição de óxido de prata, foram prejudicadas pelas espécies $\mathrm{Ag}^{2+}$, altamente oxidantes. A redissolução anódica, via deposição de prata metálica em uma superfície de um eletrodo de DDB usando o ultra-som, acoplada com a SWV, foi empregada com sucesso para a análise de traços de íons prata. O limite de detecção para $\mathrm{Ag}^{+}$foi estimado em $10^{-9} \mathrm{~mol} \mathrm{~L}^{-1}$ para uma deposição de $300 \mathrm{~s}$.

\section{Cobre}

Hardcastle e colaboradores ${ }^{85}$ aplicaram a sonoeletroanálise para a detecção de cobre em sangue humano. Um eletrodo de carbono vítreo foi utilizado para as medidas por voltametria de redissolução anódica acoplada à SWV na ausência e na presença do ultra-som, em uma solução de sangue humano $10 \%$ em eletrólito de $\mathrm{HNO}_{3}$.

Agra-Gutierrez e colaboradores ${ }^{86}$ mostraram a possibilidade de aplicação da voltametria de redissolução anódica na presença do ultra-som para a detecção de cobre total contido na cerveja, usando eletrodos de carbono vítreo e eletrodos deste material modificado com $\mathrm{Hg}$ recoberto com Nafion ${ }^{\circledR}$. Na ausência do ultra-som, foi observada a passivação do eletrodo por espécies orgânicas, diminuindo significativamente os valores dos sinais que eram medidos na presença do ultra-som. Níveis de cobre em uma faixa de 100 a $300 \mathrm{mg} \mathrm{L}^{-1}$ foram determinados usando os dois eletrodos e apresentaram valores excelentes se comparados a um método independente (espectroscopia de absorção atômica).

Hardcastle e Compton ${ }^{87}$ empregaram a extração do cobre com o solvente N-benzoil-N-fenil-hidroxilamina, como preparação da amostra para a determinação de cobre total em amostras de sangue de cavalo, usando a voltametria de redissolução anódica acoplada à SWV na presença do ultra-som.

\section{Vanádio}

Agra-Gutierrez e Compton ${ }^{88}$ realizaram a análise do complexo vanádio-catecol em um eletrodo de cobre recoberto com mercúrio, por voltametria de redissolução adsortiva na presença do ultra-som, que melhorou a sensitividade do procedimento, devido ao aumento da taxa de deposição do complexo na superfície do mercúrio, em comparação às condições na ausência do ultra-som.

Outros estudos também foram encontrados, como a detecção sonoeletroanalítica de zinco e cádmio em eletrodos de carbono vítreo modificados com filmes de bismuto ${ }^{89}$, detecção sonoeletroanalítica de metais pesados em mucosas de peixes ${ }^{90}$, análise de metais e compostos orgânicos ${ }^{91}$, traços de metais ${ }^{92}$ e detecção sonoeletroquímica de nitrito ${ }^{73}$ e nitrato ${ }^{93}$.

\section{Compostos orgânicos}

A aplicação do poder do ultra-som para a detecção de compostos orgânicos ainda é bastante escassa, visto que poucos trabalhos foram encontrados na literatura. Saterlay e colaboradores ${ }^{44}$ apresentaram a combinação do ultra-som de alta intensidade com o eletrodo de DDB, permitindo o desenvolvimento de um sensor voltamétrico aquoso para a detecção de 4-clorofenol (4-CF). A habilidade do ultrasom em regenerar a superfície do eletrodo, por meio da erosão cavitacional do 4-CF eletrodepositado, facilitou a reprodutibilidade do sinal oxidativo na presença do ultra-som em meios de ácidos diluídos, com o aumento no transporte de massa, oferecendo melhora na sensitividade. $\mathrm{O}$ limite de detecção obtido foi de $1,0 \times 10^{-6} \mathrm{~mol}$

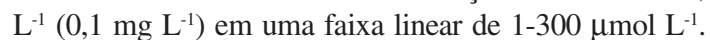

Já citado anteriormente, Zanotto-Neto ${ }^{48}$ mostrou a utilização da radiação do ultra-som em conjunto com diversas técnicas voltamétricas usando o eletrodo de DDB para a determinação eletroanalítica do 4-nitrofenol (4-NF) em águas puras e naturais (águas de rio).

Hardcastle e colaboradores ${ }^{94}$ utilizaram a sonoeletroanálise bifásica (etanol e etil acetoacetato) para a determinação de vanilina em essências naturais. Em contraste com a voltametria na ausência do ultra-som, este facilitou a emulsificação e extração da vanilina, permitindo a obtenção de um melhor sinal voltamétrico.

Beckett e colaboradores ${ }^{95}$ relataram a detecção eletroquímica do anti-inflamatório ácido 5-aminossalicílico (5-ASA) por voltametria de varredura linear, de onda quadrada e de varredura sonolinear sobre eletrodos de carbono vítreo e de platina. Foi observada uma significativa melhora na intensidade do sinal de oxidação permitindo a detecção de baixas concentrações com uma faixa linear de 1-57 $\mu \mathrm{mol} \mathrm{L} \mathrm{L}^{-1}$, adequada para aplicação do método desenvolvido em amostras fisiológicas. A eficácia do emprego da voltametria de varredura sonolinear para a determinação deste composto em meios complexos de tecidos foi avaliada com níveis de recuperação de $102 \%$. Em outro trabalho, Beckett e colaboradores $^{33}$ mostraram a detecção sonovoltamétrica da dopamina em ovos utilizando um eletrodo de carbono vítreo.

Akkermans e colaboradores ${ }^{96}$ mostraram a combinação da detecção eletroanalítica do ácido ascórbico por sonovoltametria e por voltametria de remoção por laser. Um outro trabalho de Akkermans et al..$^{97}$ mostrou a comparação de técnicas eletroanalíticas (sonovoltametria pulsada e voltametria de remoção por laser) para a detecção da vitamina $\mathrm{C}$ em sucos de frutas. Compton e Matysik $^{98}$ analisaram o comportamento sonovoltamétrico do ácido ascórbico e do ácido deidroascórbico sobre eletrodos de carbono vítreo usando a sonovoltametria pulsada.

Na Tabela 1 estão apresentados os trabalhos referentes à determinação sonoeletroanalítica de metais e de alguns compostos orgânicos em diversas matrizes complexas, sobre diferentes tipos de eletrodo de trabalho, bem como os valores dos limites de detecção obtidos para uma variedade de métodos aplicados.

\section{USO DO ULTRA-SOM NA DEGRADAÇÃO DE COMPOSTOS}

\section{Degradação direta de poluentes}

Uma das aplicações tecnológicas avançadas de oxidação para 
Tabela 1. Resumo das aplicações da sonoeletroanálise para determinações de metais e de compostos orgânicos em diferentes amostras

\begin{tabular}{|c|c|c|c|c|}
\hline Análise & Método* & Eletrodo & LDs & Ref. \\
\hline $\mathrm{Cd}^{2+}$ em eletrólito & SWV-ASV & DDB & $\begin{array}{l}\text { Sem US: } 2,5 \times 10^{-8} \mathrm{~mol} \mathrm{dm}^{-3} \\
\text { Com US: } 3,9 \times 10^{-9} \mathrm{~mol} \mathrm{dm}^{-3}\end{array}$ & 75 \\
\hline $\begin{array}{l}\mathrm{Cd}^{2+} \text { e } \mathrm{Zn}^{2+} \text { em } \\
\text { shampoo e } \\
\text { pasta dentária }\end{array}$ & SWV-ASV & Carbono vítreo e DDB & 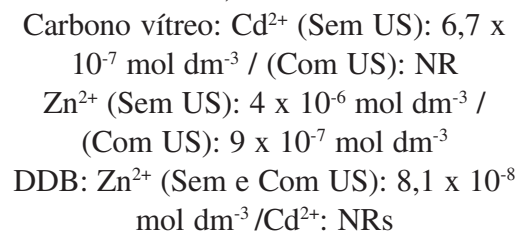 & 76 \\
\hline $\mathrm{Cd}^{2+} \mathrm{em}$ sangue & DPV-ASV & $\begin{array}{l}\text { Carbono vítreo modificado } \\
\text { com } \mathrm{Hg} \text { recoberto com Nafion }\end{array}$ & NR & 77 \\
\hline $\begin{array}{l}\mathrm{Pb}^{2+} \text { em } \\
\text { sedimentos de rio }\end{array}$ & $\begin{array}{l}\text { SWV-CSV } \\
\text { LSV-CSV }\end{array}$ & DDB & $\begin{array}{c}\text { LSV: NRs } \\
\text { SWV: Sem US: NR } \\
\text { Com US: } 10^{-8} \text { a } 10^{-7} \mathrm{~mol} \mathrm{~L}^{-1}\end{array}$ & 43 \\
\hline $\mathrm{Pb}^{2+}$ em vinho & LSV-ASV & Pt recoberto com $\mathrm{Hg}$ & $\mathrm{NR}$ & 32 \\
\hline $\begin{array}{l}\mathrm{Pb}^{2+} \text { em soluções } \\
\text { aquosas }\end{array}$ & LSV-ASV & $\begin{array}{l}\text { Sonotrodos (carbono } \\
\text { vítreo, } \mathrm{Au}, \mathrm{Cu}, \mathrm{Pt})\end{array}$ & $\begin{array}{c}\text { Sem US: NRs } \\
\text { Sonotrodo Pt } \leq 10^{-10} \text { mol L }{ }^{-1}(\mathrm{com} \text { US }) \\
\text { Outros: NRs }\end{array}$ & 78 \\
\hline $\mathrm{Pb}^{2+}$ em petróleo & LSV-ASV & Pt recoberto com $\mathrm{Hg}$ & NR & 79 \\
\hline $\mathrm{Pb}^{2+}$ em saliva & $\begin{array}{l}\text { LSV-ASV } \\
\text { SWV-ASV }\end{array}$ & $\begin{array}{l}\text { Carbono vítreo e Carbono } \\
\text { vítreo modificado com } \mathrm{Hg} \\
\text { recoberto com Nafion }\end{array}$ & $\begin{array}{c}\text { Sem US: NR } \\
\text { Com US (SWV): } 0,25 \mu \mathrm{g} \mathrm{L}{ }^{-1} \\
\text { LSV: NRs }\end{array}$ & 42 \\
\hline $\mathrm{Mn}^{2+}$ em chá & DPV-CSV & DDB & $\begin{array}{c}\text { Sem US: NR } \\
\text { Com US: } 10^{-11} \mathrm{~mol} \mathrm{~L}^{-1}\end{array}$ & 80 \\
\hline $\mathrm{Mn}^{2+}$ em águas de rio & DPV-CSV & DDB & $\begin{array}{l}\text { Sem US: } 1 \times 10^{-7} \mathrm{~mol} \mathrm{~L}^{-1} \\
\text { Com US: } 8,9 \times 10^{-9} \mathrm{~mol} \mathrm{~L}^{-1}\end{array}$ & 81 \\
\hline $\mathrm{As}^{3+}$ em eletrólito & SWV-ASV & Prata, platina e ouro & $\begin{array}{c}\text { Prata: Sem US: } 6,3 \times 10^{-7} \mathrm{~mol} \mathrm{~L}^{-1} \\
\text { Com US: } 1,4 \times 10^{-8} \mathrm{~mol} \mathrm{~L}^{-1} \\
\text { Outros: NRs }\end{array}$ & 82 \\
\hline $\mathrm{As}^{3+}$ em águas de rio & SWV-ASV & Ouro & $\begin{array}{l}\text { Sem US: } 1,8 \times 10^{-7} \mathrm{~mol} \mathrm{~L}^{-1} \\
\text { Com US: } 1 \times 10^{-8} \mathrm{~mol} \mathrm{~L}^{-1}\end{array}$ & 83 \\
\hline $\mathrm{Ag}^{+}$no eletrólito & $\begin{array}{l}\text { LSV e SWV- } \\
\text { CSV / ASV }\end{array}$ & DDB & $\begin{array}{l}\text { SWV-ASV: Sem US: NR } \\
\text { Com US: } 10^{-9} \mathrm{~mol} \mathrm{~L}^{-1}\end{array}$ & 84 \\
\hline $\mathrm{Cu}^{2+}$ em sangue & SWV-ASV & Carbono vítreo & $\mathrm{NR}$ & 85 \\
\hline $\mathrm{Cu}^{2+}$ em cerveja & $\begin{array}{l}\text { LSV-ASV } \\
\text { SWV-ASV }\end{array}$ & $\begin{array}{l}\text { Carbono vítreo e Carbono } \\
\text { vítreo modificado com } \mathrm{Hg} \\
\text { recoberto com Nafion }{ }^{\circledR}\end{array}$ & NRs & 86 \\
\hline $\begin{array}{l}\mathrm{Cu}^{2+} \text { em sangue } \\
\text { de cavalo }\end{array}$ & SWV-ASV & Carbono vítreo & $\begin{array}{c}\text { Sem US: NR } \\
\text { Com US: } 0,16 \mu \mathrm{g} \mathrm{L}^{-1}\end{array}$ & 87 \\
\hline $\begin{array}{l}\text { Vanádio-Catecol em } \\
\text { meio aquoso }\end{array}$ & DPV-AdSV & Cobre recoberto com $\mathrm{Hg}$ & NR & 88 \\
\hline $\begin{array}{l}\mathrm{Zn}^{2+} \text { e } \mathrm{Cd}^{2+} \\
\text { em eletrólito }\end{array}$ & SWV-ASV & $\begin{array}{l}\text { Carbono vítreo modificado } \\
\text { com filmes de bismuto }\end{array}$ & $\begin{array}{l}\mathrm{Zn}^{2+}(\text { Sem US }): 4,3 \times 10^{-7} \mathrm{~mol} \mathrm{~L}^{-1} \\
\text { (Com US): } 2,2 \times 10^{-7} \mathrm{~mol} \mathrm{~L}^{-1} \mathrm{Cd}^{2+} \\
\quad \text { (Sem US): } 1,08 \times 10^{-6} \mathrm{~mol} \mathrm{~L}^{-1} \\
\quad \text { (Com US): } 6 \times 10^{-9} \mathrm{~mol} \mathrm{~L}^{-1}\end{array}$ & 89 \\
\hline $\begin{array}{l}\mathrm{Cu}^{2+}{\mathrm{e} \mathrm{Pb}^{2+} \text { em }}_{\text {mucosas de peixes }}\end{array}$ & SWV-ASV & $\begin{array}{l}\text { Carbono vítreo recoberto } \\
\text { com filme fino de } \mathrm{Hg}\end{array}$ & $\begin{array}{c}\text { Chumbo: NRs } \\
\text { Cobre: Sem US: NR } \\
\text { Com US: } 4 \mu \mathrm{g} \mathrm{L}^{-1}\end{array}$ & 90 \\
\hline $\begin{array}{l}\text { Complexo Vanádio- } \\
\text { catecol, } \mathrm{Ni}^{2+} \\
\text { Riboflavina (RF) } \\
\text { em eletrólito }\end{array}$ & $\begin{array}{l}\text { DPV-AdSV } \\
\text { SWV-AdSV } \\
\text { SWV-CSV }\end{array}$ & $\begin{array}{l}\text { Cobre e carbono vítreo } \\
\text { recoberto com } \mathrm{Hg}\end{array}$ & $\begin{array}{c}\text { Complexo: Sem US: NR } \\
\text { Com US: } 2 \times 10^{-8} \mathrm{~mol} \mathrm{~L}^{-1} \\
\mathrm{Ni}^{2+}: \text { NRs } \\
\text { RF: sem US: NR } \\
\text { Com US: } 2 \times 10^{-9} \mathrm{~mol} \mathrm{~L}^{-1}\end{array}$ & 91 \\
\hline $\mathrm{Cu}^{2+}$ e $\mathrm{Pb}^{2+}$ em eletrólito & LSV-ASV & Carbono vítreo & NRs & 92 \\
\hline Nitrito em ovos & LSV & Carbono vítreo & $\begin{array}{c}\text { Sem US: NR } \\
\text { Com US: } 1 \times 10^{-6} \mathrm{~mol} \mathrm{~L}^{-1}\end{array}$ & 73 \\
\hline $\begin{array}{l}\text { Nitrato em efluentes } \\
\text { contaminados }\end{array}$ & LSV & Cobre modificado & $\mathrm{NR}$ & 93 \\
\hline $\begin{array}{l}\text { 4-clorofenol em } \\
\text { meio aquoso }\end{array}$ & $\mathrm{VC}$ & DDB & $\begin{array}{c}\text { Sem US: NR } \\
\text { Com US: } 1 \times 10^{-6} \mathrm{~mol} \mathrm{~L}^{-1}\end{array}$ & 44 \\
\hline
\end{tabular}


Tabela 1. continuação

\begin{tabular}{|c|c|c|c|c|}
\hline Análise & Método* & Eletrodo & LDs & Ref. \\
\hline $\begin{array}{l}\text { Vanilina em essências } \\
\text { naturais }\end{array}$ & $\begin{array}{l}\text { LSV } \\
\text { SWV }\end{array}$ & Carbono vítreo & $\begin{array}{c}\text { Sem US: NRs } \\
\text { Com US (SWV): } 1,6 \text { a } 2,0 \text { × } 10^{-5} \mathrm{~mol} \mathrm{~L}^{-1}\end{array}$ & 94 \\
\hline $\begin{array}{l}\text { 5-ASA em amostras } \\
\text { fisiológicas }\end{array}$ & $\begin{array}{l}\text { LSV } \\
\text { SWV } \\
\text { Sono-LSV }\end{array}$ & Carbono vítreo ou platina & $\begin{array}{c}\text { LSV: } 5 \times 10^{-6} \mathrm{~mol} \mathrm{~L}^{-1} \\
\text { SWV: } 3,6 \times 10^{-6} \mathrm{~mol} \mathrm{~L}^{-1} \\
\text { Sono-LSV: } 0,3 \times 10^{-6} \mathrm{~mol} \mathrm{~L}^{-1}\end{array}$ & 95 \\
\hline Dopamina em ovos & LSV & Carbono vítreo & $\begin{array}{c}\text { Sem US: NR } \\
\text { Com US: } 0,85 \times 10^{-6} \mathrm{~mol} \mathrm{~L}^{-1}\end{array}$ & 33 \\
\hline $\begin{array}{l}\text { Vitamina } \mathrm{C} \text { em } \\
\text { sucos de frutas }\end{array}$ & $\begin{array}{l}\text { PS-LSV } \\
\text { LAV }\end{array}$ & Platina & NRs & 97 \\
\hline
\end{tabular}

* na ausência e na presença do ultra-som. Ultra-som (US), NR: não relatado, LD: limite de detecção. LSV: voltametria de varredura linear, SWV: voltametria de onda quadrada, DPV: voltametria de pulso diferencial, ASV: voltametria de redissolução anódica, CSV: voltametria de redissolução catódica, AdSV: voltametria de redissolução adsortiva, PS: sonovoltametria pulsada, LAV: voltametria de remoção por laser.

aplicações em tratamentos de efluentes é o uso do ultra-som, pois acelera a destruição de contaminantes na fase líquida ${ }^{99-102}$. Há três regiões importantes que devem ser consideradas em relação aos processos sonoquímicos em meio aquoso. A primeira região é o interior do colapso das bolhas de cavitação no qual existem condições termodinâmicas extremas, devido às altas temperaturas e pressões ${ }^{103-107}$. Nesta região, acontece a rápida pirólise dos solutos voláteis. As moléculas de água sofrem decomposição térmica para produzir átomos de $\mathrm{H}$ e radicais $\cdot \mathrm{OH}$, fortes oxidantes não seletivos de poluentes orgânicos presentes em efluentes ${ }^{12,13,108-110}$. A segunda região é o limite interfacial entre as fases líquida e gasosa onde a temperatura é mais baixa que dentro das bolhas, mas ainda alta, para causar a decomposição térmica de solutos orgânicos. Acredita-se que os radicais reativos estejam localizados majoritariamente nesta região. A terceira região é o seio da solução (normalmente em temperatura ambiente) onde podem acontecer diversas reações entre os solutos orgânicos e os radicais ${ }^{111}$.

$\mathrm{Na}$ fase líquida, uma concentração constante das espécies radicais reativas é mantida por meio da irradiação contínua do ultrasom. Apesar da geração de radicais · OH ser a chave da decomposição eficiente de materiais orgânicos, a recombinação de $\cdot \mathrm{OH}$ para produzir $\mathrm{H}_{2} \mathrm{O}_{2}$ ambos na fase gasosa das bolhas ou na fase líquida da solução, é o principal processo que limita a quantidade de radicais reativos acessíveis para as moléculas orgânicas. Esta limitação resulta em uma perda de eficiência global, já que o $\mathrm{H}_{2} \mathrm{O}_{2}$ gerado sonoquimicamente, por si só, não pode reagir com a molécula orgânica desejada e com isso decompô-la ${ }^{112}$.

A robustez mecânica e a natureza altamente inerte dos eletrodos de DDB fazem-nos ideais para uso em eletroquímica, na ausência e na presença do ultra-som, particularmente na oxidação de materiais orgânicos em efluentes ${ }^{113}$.

Foord e colaboradores ${ }^{113}$ mostraram a oxidação parcial direta do corante azul da Prússia (massa molar relativamente alta de $840 \mathrm{~g}$ $\mathrm{mol}^{-1}$ ) sobre um eletrodo de DDB em meio de tampão fosfato, mudando o pH e a concentração do corante. Observou-se, em meio de tampão fosfato a $\mathrm{pH} 2$, a oxidação parcial com a transferência de quatro elétrons, dentro da janela eletroquímica em até $2,5 \mathrm{~V} v s$ eletrodo de calomelano saturado (SCE). Porém, uma degradação mais extensa do azul de Prússia não aconteceu a potenciais mais baixos em relação aos potenciais requeridos para a decomposição do solvente, mostrando que o corante precisa de altos sobrepotenciais ou da presença de algum catalisador. Concluiu-se que a degradação é facilitada quando o $\mathrm{pH}$ do meio é acido e quando o corante está presente em baixas concentrações. Holt e colaboradores ${ }^{70}$ mostraram posteriormente que uma estimativa aproximada do coeficiente de difusão para o composto em água, D: $0,3 \times 10^{-9} \mathrm{~m}^{2} \mathrm{~s}^{-1}$ (valor relativamente baixo), permite o cálculo da espessura da camada de difusão para o sistema $(0,3 \mu \mathrm{m})$ utilizando dados sonovoltamétricos e a Equação 1. Este valor é surpreendentemente pequeno e sugere um transporte de massa muito rápido para este tipo de composto, com baixa tendência à difusão. Ou seja, em relação a processos hidrodinâmicos convencionais sob controle do transporte de massa, com um sistema de transdutor ultra-sônico em forma de ponta, moléculas com grandes volumes e massas moleculares sofrem uma eletrólise mais eficiente. Em suma, estes trabalhos mostram que a presença da radiação aumentou o transporte do corante até o eletrodo, que pode resultar em uma degradação mais eficiente, mesmo este não apresentando tendência à difusão.

Holt e colaboradore s $^{114}$ mostraram o poder do ultra-som na descoloração anódica do reagente N,N-dimetil-p-nitrosoanilina sobre o eletrodo de DDB. Este processo ocorre predominantemente via reação com radicais hidroxila. Neste estudo, foram comparados três tipos de DDB altamente dopado (aproximadamente $10^{20}$ $\mathrm{cm}^{-3}$ ) de diferentes procedências. $\mathrm{O}$ estado da superfície dos eletrodos de diamante aparece como um parâmetro importante. O diamante com um alto conteúdo de carbono grafite produz altas quantidades de radicais. A introdução de carbono $\mathrm{sp}^{2}$ à superfície do eletrodo resulta em um aumento na eficiência de descoloração do composto, sugerindo que os sítios de impureza $\mathrm{sp}^{2}$ podem estar diretamente associados com a formação de radicais hidroxila. Porém, o transporte de massa é o parâmetro que controla a eficiência do processo de oxidação.

A oxidação sonoeletroquímica tem-se mostrado também eficiente na degradação de moléculas orgânicas no tratamento de efluentes utilizando outros materiais eletródicos que não seja o DDB. A seguir, são revisados os trabalhos encontrados na literatura a este respeito.

Trabelsi e colaboradores ${ }^{34}$ realizaram a oxidação de um poluente modelo, o fenol, em um reator usando um eletrodo cilíndrico de ouro como eletrodo de trabalho (diâmetro de $1 \mathrm{~mm}$ ), utilizando somente o ultra-som e este, associado à eletrólise. Com sonicação de $20 \mathrm{kHz}$, a oxidação eletroquímica do fenol em meio de $\mathrm{NaCl}$ permitiu a conversão de $75 \%$ do fenol inicial em 10 min de tratamento. Porém, um intermediário tóxico, a p-quinona, foi formado. Usando $500 \mathrm{kHz}$ (produção de maior quantidade de radicais $\mathrm{OH} \bullet$ em meio aquoso em relação a fontes de baixas frequiências, 20 $\mathrm{KHz}$ ), uma conversão de $95 \%$ do fenol inicial foi obtida dentro do mesmo tempo de tratamento. Neste caso, os produtos finais da degradação foram ácidos acético e cloroacrílico. Visto que a eletrólise do fenol gera um acúmulo de gás e a presença de depósitos sólidos no eletrodo, a utilização da radiação a baixa frequência foi mais efetiva para a remoção desse gás e para a limpeza da superfície 
eletródica, enquanto que a altas frequiências, a radiação foi mais eficiente na degradação do poluente.

Macounova e colaboradores ${ }^{115}$ realizaram o estudo da degradação do herbicida diuron [3-(3,4-diclorofenil)-1,1-dimetiluréia] em um ânodo de carbono vítreo usando o ultra-som para evitar o bloqueio da superfície do eletrodo por um filme passivador. Identificaram três produtos de degradação (dímeros), mas concluíram que foram geradas várias espécies secundárias não identificadas que poderiam envolver processos de oxidação multieletrônica, mostrando que o processo de oxidação global do diuron requer a transferência de mais de um elétron.

Lima Leite e colaboradores ${ }^{116}$ investigaram a eletro-oxidação do ácido 2,4-diidroxibenzóico sobre um eletrodo de platina com o uso do ultra-som em duas frequiências (20 e $500 \mathrm{kHz}$ ). A baixas freqüências, as taxas de transferência de massa das espécies eletroativas para a superfície de eletrodo como também os mecanismos de adsorção/dessorção são acelerados, enquanto que, a altas frequiências, os radicais hidroxila são gerados, oxidando diretamente os poluentes orgânicos. Para uma concentração inicial do composto orgânico (300 mg L $\mathrm{mg}^{-1}$ ) e usando uma densidade de corrente de $300 \mathrm{~A} \mathrm{~m}^{-2}$, a diminuição do carbono orgânico total (COT) foi de $47 \%$, passando uma quantidade de eletricidade de $1,5 \mathrm{~A} \mathrm{~h}$ a baixa frequiência, mostrando o efeito benéfico do ultra-som na degradação deste composto.

$\mathrm{O}$ uso do ultra-som aliado às técnicas eletroquímicas também foi avaliado na degradação de corantes. Lorimer e colaboradores ${ }^{117}$ mostraram a descolorização do Amarelo de Sandolin pela eletrólise da tintura em solução salina aquosa usando eletrodos de platina. O processo, baseando-se na eletrólise de uma solução de cloreto de metal alcalino (no caso, cloreto de sódio), produz hipoclorito, liberando o gás cloro no ânodo e íons hidróxido no cátodo, resultando na geração in situ de íons hipoclorito, um poderoso oxidante (Equações 2 a 4). Este processo é melhorado pelo uso do ultra-som aliado à eletrólise e um ótimo poder acústico foi observado ao se usar uma freqüência de $20 \mathrm{kHz}$.

Ânodo: $2 \mathrm{Cl}^{-} \rightarrow \mathrm{Cl}_{2}+2 \mathrm{e}$

Cátodo: $2 \mathrm{e}+2 \mathrm{H}_{2} \mathrm{O} \rightarrow 2 \mathrm{OH}^{-}+\mathrm{H}_{2}$

Reação global: $2 \mathrm{OH}^{-}+\mathrm{Cl}_{2} \rightarrow \mathrm{Cl}^{-}+\mathrm{OCl}^{-}+\mathrm{H}_{2} \mathrm{O}$

\section{Tratamento de efluentes de modo indireto}

Por outro lado, a aplicação dos processos sonoeletroquímicos aliados a outros métodos de oxidação indireta para a oxidação de compostos orgânicos tem surgido recentemente como excelente ferramenta para o tratamento de efluentes ${ }^{112,118,119}$. Neste sentido, a reação de Fenton é bem conhecida na destruição de material orgânico por meio da geração extra de radicais hidroxila, Equação 5:

$\mathrm{Fe}^{2+}+\mathrm{H}_{2} \mathrm{O}_{2} \rightarrow \mathrm{Fe}^{3+}+\mathrm{OH}^{-}+\cdot \cdot \mathrm{OH}$

Abdelsalam e Birkin ${ }^{112}$ estudaram a degradação do corante azul de meldola sob a influência do ultra-som em combinação ao $\mathrm{H}_{2} \mathrm{O}_{2}$ gerado eletroquimicamente (redução do oxigênio molecular). Observaram que esta concentração de $\mathrm{H}_{2} \mathrm{O}_{2}$ e aquela gerada pelo ultrasom não é altamente ativa para a destruição de espécies orgânicas. Para isto foi utilizada a reação de Fenton (Equação 5), permitindo uma máxima geração de radicais livres em solução, especificamente radicais hidroxila. $\mathrm{O}$ efeito da adição de $\mathrm{Fe}^{2+}$ na taxa de degradação do corante mostrou-se muito significante. Nas condições otimizadas, a constante de velocidade da degradação do corante alcançou um valor máximo de 23,7 $\pm 0,35 \times 10^{-3} \mathrm{~min}^{-1}$, assumindo uma cinética de pseudo-primeira ordem. A constante de velocida- de para a destruição completa do azul de meldola, determinada por meio da demanda química de oxigênio foi significativamente mais lenta e estimada em 10,2 $\pm 2,6 \times 10^{-3} \mathrm{~min}^{-1}$.

Abramov e colaboradores ${ }^{118}$ desenvolveram recentemente um método que combina o tratamento sonoeletroquímico com a adição de ozônio para a destruição do 1,3-dinitrobenzeno e do 2,4dinitrotolueno em soluções aquosas. É conhecido que o ozônio molecular em soluções aquosas é um dos agentes oxidantes mais ativos. A interação do ozônio com o doador de elétrons, D, ou pela redução no cátodo, leva à formação do íon $\mathrm{O}_{3}$.

$\mathrm{O}_{3}+\mathrm{e}^{-}(\mathrm{D}) \rightarrow \mathrm{O}_{3}^{-}\left(+\mathrm{D}^{+}\right)$

Este íon é um oxidante mais forte que o ozônio molecular e, em meio ácido, rapidamente sofre uma reação com formação do ânion radical $\mathrm{O}^{-\bullet}$ e oxigênio.

$\mathrm{O}_{3}^{-} \rightarrow \mathrm{O}^{-\bullet}+{ }^{1} \mathrm{O}_{2}$

Alternativamente, este pode interagir com a água, formando oxigênio, íon hidroxila e radical $\mathrm{OH} \bullet$.

$\mathrm{O}_{3}^{-}+\mathrm{H}_{2} \mathrm{O} \rightarrow \mathrm{HO} \bullet+{ }^{1} \mathrm{O}_{2}+\mathrm{HO}^{-}$

Além disso, a redução catódica do ozônio gera agentes oxidantes altamente ativos. Durante a passagem do ozônio, sua redução ocorre preferencialmente em relação aos nitrocompostos. Apesar da provável formação de íons $\mathrm{O}_{3}^{-}$mais reativos no cátodo, a destruição por oxidação dos compostos ocorre muito vagarosamente sem o uso de ultra-som. Porém, a aplicação simultânea do ultra-som e da ozonização na reação permitiu a destruição quase completa dos compostos em tempos menores. O efeito atribuído ao processo ultrasônico-eletroquímico foi o aumento na produção de intermediários suscetíveis à oxidação pelo ozônio.

Yasman e colaboradores ${ }^{119}$ desenvolveram um método para a detoxificação de poluentes cloro-orgânicos hidrofílicos em águas de efluentes. Utilizaram uma combinação do ultra-som com a eletroquímica e o reagente de Fenton. As vantagens do método foram exemplificadas usando dois herbicidas comuns: o ácido 2,4diclorofenoxiacético (2,4-D) e o seu derivado 2,4-diclorofenol (2,4DCP). O alto poder de degradação proveniente deste processo foi em virtude da grande produção de radicais hidroxila oxidantes e da alta transferência de massa devido à sonicação. A aplicação deste processo de tratamento sonoeletroquímico Fenton (SEF) (a $20 \mathrm{kHz}$ ) usando uma densidade de corrente pequena $(100 \mathrm{~mA})$ resultou na degradação praticamente completa do herbicida 2,4-D em solução (300 ppm; 1,2 mM) em 600 s e também uma oxidação considerável do 2,4-DCP. A eficiência do processo SEF foi muito maior comparada aos métodos de degradação convencionais e os tempos requeridos para degradação completa são consideravelmente mais curtos. A concentração ótima dos íons de $\mathrm{Fe}^{2+}$ requerida para este processo foi cerca de $2 \mathrm{mM}$, valor mais baixo ao usado em técnicas de referência.

\section{AUXÍLIO NO ENTENDIMENTO DE MECANISMOS DE REAÇÃO}

Alguns trabalhos foram encontrados a respeito de como o ultrasom aliado à eletroquímica pode prover informações mecanísticas e/ou cinéticas de um processo eletródico. Ionita e colaboradores ${ }^{120}$ mostraram que a oxidação sonoeletroquímica do álcool isopropílico é um processo complexo e a frequiência do ultra-som é um fator decisivo no processo global. A baixa freqüência $(40 \mathrm{kHz})$ o processo está baseado em um mecanismo reversível tipo EQ (eletroquímico- 
químico) com a reação química, sendo a etapa determinante da velocidade, enquanto que a altas frequiências $(500 \mathrm{kHz})$ a energia provida ao sistema eletroquímico é suficientemente alta para gerar outras reações químicas prevalecentes, que governam o processo de oxidação global.

Pollet e colaboradores ${ }^{121}$ mostraram o efeito do ultra-som na oxidação de tiossulfato sobre eletrodos de platina e de aço. Observaram que o ultra-som aumenta significativamente a velocidade de oxidação do tiossulfato (50 vezes) se comparada à reação na ausência do ultra-som. Observaram, também, que com o aumento na potência do ultra-som houve um deslocamento do potencial de oxidação no sentido anódico, possivelmente devido à formação de radicais hidroxila, mudanças na composição da superfície eletródica e fenômenos complexos de adsorção. $\mathrm{O}$ aumento da sensitividade dos picos de oxidação e na velocidade de decomposição do tiossulfato na presença do ultra-som justifica-se pelo aumento na transferência de massa para o eletrodo, devido à cavitação e ao fluxo acústico associado a fenômenos complexos de adsorção.

Banks e colaboradores ${ }^{122}$ estudaram a oxidação eletroquímica da dimetil-p-fenilenediamina em solução aquosa (tampão fosfato pH 7) na ausência e na presença do ultra-som. Foi observado, na presença do ultra-som, um ombro na onda da varredura. Este efeito foi atribuído a um processo de transferência de dois elétrons, que ocorre simultaneamente. A transferência do primeiro elétron é relativamente rápida $\left(0,1 \mathrm{~cm} \mathrm{~s}^{-1}\right)$ seguida pelo segundo elétron, um processo mais lento. Em virtude do rápido transporte de massa resultante do ultra-som, houve a produção de um sobrepotencial difusional para este segundo elétron, em comparação ao primeiro, sendo observado na resposta voltamétrica.

\section{PERSPECTIVAS}

Vários trabalhos foram encontrados na literatura a respeito da sonoeletroanálise para a detecção de metais em meios altamente passivadores, como sangue, sedimentos de rio, vinho etc. Entretanto, notou-se uma escassez de trabalhos para a detecção de compostos orgânicos, o que seria muito promissor no caso de compostos altamente tóxicos, como os pesticidas. Portanto, julga-se necessário desenvolver metodologias para a detecção de pesticidas em meios altamente hostis, bem como maneiras de usar a combustão eletroquímica associada ao ultra-som, para eliminar esses compostos e subprodutos presentes em diversas matrizes ambientais.

\section{CONCLUSÕES}

Os efeitos do aumento no transporte de massa de espécies eletroativas e de limpeza da superfície eletródica fazem do ultrasom uma ferramenta viável para a detecção de substâncias em amostras complexas. Entretanto, a sonoeletronálise de compostos orgânicos em matrizes consideradas hostis não é amplamente explorada se comparada à análise de metais. Deste modo, este trabalho de revisão buscou reunir os trabalhos que mostram a aplicabilidade do ultra-som aliado à eletroquímica para a análise de compostos orgânicos.

A combustão eletroquímica de compostos orgânicos e subprodutos (produtos de degradação) utilizando a sonoeletroquímica também não foi abordada em trabalhos de revisão já existentes. Sendo assim, foram apresentados trabalhos que relatam a combustão direta e indireta (por exemplo, aliada à reação de Fenton) de compostos tóxicos presentes em efluentes contaminados, tais como pesticidas e corantes. Assim, evidenciou-se a importância da utilização do ultra-som em eletroquímica objetivando a degradação de poluentes.

\section{AGRADECIMENTOS}

Ao CNPq (Proc. 142930/2005-9) e a FAPESP (Proc. 06/50692-2) pelas bolsas e apoios financeiros concedidos.

\section{REFERÊNCIAS}

1. Compton, R. G.; Eklund, J. C.; Marken F.; Electroanalysis 1997, 9, 509.

2. Banks, C. E.; Compton, R. G.; Chem. Anal. 2003, 48, 159.

3. Banks, C. E.; Compton, R. G.; Electroanalysis 2003, 15, 329.

4. Saterlay, A. J.; Compton, R. G.; Fresenius J. Anal. Chem. 2000, 367, 308.

5. Banks, C. E.; Compton, R. G.; Analyst 2004, 129, 678.

6. Mason, T. J. Em Sonochemistry: the uses of ultrasound in chemistry; Mason, T. S., ed.; The Royal Society of Chemistry: Cambridge, 1990, cap. 1, p. 1.

7. Martines, M. A. U.; Davolos, M. R.; Jafellici-Junior, M.; Quim. Nova 2000, 23, 251.

8. Davidson, R. S. Em ref. 6, cap. 6, p. 69.

9. Lorimer, J. P.; Em ref. 6, cap. 9, p. 113.

10. Donaldson, D. J.; Farrington, M. D.; Kruus, P.; J. Phys. Chem. 1979, 83, 3130.

11. Suslick, K. S.; Flint, E. B.; Nature 1987, 330, 553.

12. Makino, K.; Mossoba, M. M.; Riesz, P.; J. Am. Chem. Soc. 1982, 104, 3537.

13. Makino, K.; Mossoba, M. M.; Riesz, P.; J. Phys. Chem. 1983, 87, 1369.

14. Atobe, M.; Tonoi, T.; Nonaka, T.; Electrochem. Commun. 1999, 1, 593.

15. Atobe M.; Nonaka, T.; Chem. Lett. 1997, 323.

16. Marken, F.; Compton, R. G.; Electrochim. Acta 1998, 43, 2157.

17. Compton, R. G.; Eklund, J. C.; Marken, F.; Rebbitt, T. O.; Akkermans, R. P.; Walker, D. N.; Electrochim. Acta 1997, 42, 2919.

18. Perusich, S. A.; Alkire, R. C.; J. Electrochem. Soc. 1991, 138, 700.

19. Klima, J.; Bernard, C.; Degrand, C.; J. Electroanal. Chem. 1994, 367, 297.

20. Birkin, P. R.; Martinez, S. S.; Anal. Chem. 1997, 69, 2055.

21. Cooper, E. L.; Coury, L. A.; J. Electrochem. Soc. 1998, 145, 1994.

22. Agra-Gutierrez, C.; Ball, J. C.; Compton, R. G.; J. Phys. Chem. B 1998, 102, 7028.

23. Del Campo, F. J.; Meville, J.; Hardcastle, J. L.; Compton, R. G.; J. Phys. Chem. A 2001, 105, 666.

24. Walton, D. J.; Phull, S. S.; Adv. Sonochem. 1996, 4, 205.

25. Kotronarou, A.; Millis, G.; Hoffmann.; J. Phys. Chem. 1991, 95, 3630.

26. Caulier, T. P.; Maeck, M.; Reisse, J.; J. Org. Chem. 1995, 60, 272.

27. Misik, V.; Kirschenbaum, L. J.; Riesz, P.; J. Phys. Chem. 1995, 99, 5970.

28. Suslick, K. S.; Doktycz, S. J.; Adv. Sonochem. 1990, 1, 173.

29. Henglein, D.; Herburger, D.; Gutierrez, M.; J. Phys. Chem. 1992, 96, 1126.

30. Banks, C. E.; Compton, R. G.; Chem. Phys. Chem. 2003, 4, 169.

31. Matysik, F. M.; Matysik, S.; Brett, A. M. O.; Brett, C. M. A.; Anal. Chem. 1997, 69, 1651.

32. Akkermans, R. P.; Ball, J. C.; Rebbitt, J. O.; Marken F.; Compton, R. G.; Electrochim. Acta 1998, 43, 3443.

33. Beckett, E. L.; Lawrence, N. S.; Tsai, Y. C.; Davis, J.; Compton, R. G.; J. Pharm. Biomed. Anal. 2001, 26, 995.

34. Trabelsi, F.; Ait-Lyazidi, H.; Ratsimba, B.; Wilhelm, A. M.; Delmas, H.; Fabre, P. L.; Berlan, J.; Chem. Eng. Sci. 1996, 51, 1857.

35. Mason, T. J.; Lorimer, J. P.; Bates, D. M.; Ultrasonics 1992, 30, 40.

36. Lorimer, J. P.; Pollet, B.; Phull, S. S.; Mason, T. J.; Walton, D. J.; Geissler, U.; Electrochim. Acta 1996, 41, 2737.

37. Walton, D. J.; Phull, S. S.; Chyla, A.; Lorimer, J. P.; Burke, L. D.; Murphy, M.; Compton R. G.; Eklund, J. C.; Page, S. D.; J. Appl. Electrochem. 1995, $25,1083$.

38. Yildiz, G.; Catalgil-Giz, H.; Giz, A.; J. Appl. Polym. Sci. 2002, 84, 83.

39. Kobayashi, K.; Chiba, A.; Minami, N.; Ultrasonics 2000, 38, 676.

40. Agullo, E.; Gonzalez-Garcia, J.; Exposito, E.; Montiel, V.; Aldaz, A.; New J. Chem. 1999, 23, 95.

41. Walton, D. J.; Phull, S. S.; Geissler, U.; Chyla, A.; Durham, A.; Ryley, S.; Mason, T. J.; Lorimer, J. P.; Electrochem. Commun. 2000, 2, 431.

42. West, C. E.; Harcastle, J. L.; Compton, R. G.; Electroanalysis 2002, 14, 1470 .

43. Saterlay, A. J.; Agra-Gutierrez, C.; Taylor, M. P.; Marken, F.; Compton, R. G.; Electroanalysis 1999, 11, 1083.

44. Saterlay, A. J.; Foord, J. S.; Compton, R. G.; Electroanalysis 2001, 13, 1065.

45. Alkire, R. C.; Perusich, S.; Corros. Sci. 1983, 23, 1121.

46. Villagrán, C.; Banks, C. E.; Pitner, W. R.; Hardacre, C.; Compton, R. G.; Ultrason. Sonochem. 2005, 12, 423.

47. Marken, F.; Compton, R. G.; Ultrason. Sonochem. 1996, 3, S131.

48. Zanotto-Neto, G.; Dissertação de Mestrado, Universidade de São Paulo, 
Brasil, 2005

49. Pedrosa, V. A.; Codognoto, L.; Avaca, L. A.; J. Braz. Chem. Soc. 2003, $14,530$.

50. Compton, R. G.; Eklund, J. C.; Page, S. D.; Sanders, G. H. M.; Booth, J.; J. Phys. Chem. 1994, 98, 12410.

51. Compton, R. G.; Eklund, J. C.; Page, S. D.; J. Phys. Chem. 1995, 99, 4211

52. Compton, R. G.; Eklund, J. C.; Page, S. D.; Rebbitt, T. O.; J. Chem. Soc Dalton Trans. 1995, 389.

53. Lee, C. W.; Compton, R. G.; Eklund, J. C.; Waller, D. N.; Ultrason. Sonochem. 1995, 2, 57.

54. Eklund, J. C.; Marken F.; Waller, D. N.; Compton, R. G.; Electrochim. Acta 1996, $41,1541$.

55. Compton, R. G.; Eklund, J. C.; Marken, F.; Waller, D. N.; Electrochim. Acta 1996, 41, 315.

56. Zhang, H.; Coury Jr, L. A.; Anal. Chem. 1993, 65, 1552.

57. Marken, F.; Kumbhat, S.; Sanders, G. H. W.; Compton, R. G.; J. Electroanal. Chem. 1996, 414, 95.

58. Compton, R. G.; Marken, F.; Goeting, C. H.; McKeown, R. A. J.; Foord, J. S.; Scarsbrook, G.; Sussmann, R. S.; Whitehead, A. J.; Chem. Commun. 1998, 1961.

59. Goeting, C. H.; Foord, J. S.; Marken, F.; Compton, R. G.; Diamond Relat. Mater. 1999, 81, 824.

60. Compton, R. G.; Eklund, J. C.; Page, S. D.; Mason, T. J.; Walton, D. J.; J. Appl. Electrochem. 1996, 26, 775.

61. Penn, R.; Yeager, E.; Hovork, F.; J. Acoust. Soc. Am. 1959, 31, 1372.

62. Hickman, R. G.; Plating 1965, 52, 407.

63. Hagan, C. R. S.; Coury Jr, L. A.; Anal. Chem. 1994, 66, 399.

64 Birkin, P. R.; Silva-Martinez, S.; J. Electroanal. Chem. 1996, 416, 127.

65. De Souza, D.; Machado, S. A. S.; Avaca, L. A.; Quim. Nova 2003, $26,81$.

66. Pedrosa, V. A.; Codognoto, L.; Machado, S. A. S.; Avaca, L. A.; J. Electroanal. Chem. 2004, 573, 11.

67. Codognoto, L.; Machado, S. A. S.; Avaca, L. A.; Diamond Relat. Mater. 2002, 11, 1670

68. Pedrosa, V. A.; Codognoto, L.; Avaca, L. A.; Quim. Nova 2003, $26,844$.

69. Pedrosa, V. A.; Miwa, D.; Machado, S. A. S.; Avaca, L. A.; Electroanalysis 2006, 18,1590

70. Holt, K. B.; del Campo, J.; Foord, J. S.; Compton, R. G.; Marken, F.; J. Electroanal. Chem. 2001, 513, 94.

71. Bagotzky, V. S.; Fundamentals of Electrochemistry, Plenum Press: New York, 1993.

72. Correia, A. N.; Mascaro, L. H.; Machado, S. A. S.; Mazo, L. H.; Avaca, L. A.; Quim. Nova 1995, 18, 475.

73. Davis, J.; Compton, R. G.; Anal. Chim. Acta 2000, 404, 241.

74. Birkin, P. R.; Offin, D. G.; Joseph, P. F.; Leighton, T. G.; J. Phys. Chem. B 2005, 109, 16997.

75. Banks, C. E.; Hyde, M. E.; Tomcik, P.; Jacobs, R.; Compton, R. G.; Talanta 2004, 62, 279.

76. Kruusma, J.; Tomcik, P.; Banks, C. E.; Compton, R. G.; Electroanalysis 2004, 16, 852 .

77. Kruusma, J.; Nei, L.; Hardcastle, J. L.; Compton, R. G.; Lust, E.; Keis, H.; Electroanalysis 2004, 16, 399.

78. Akkermans, R. P.; Ball, J. C.; Marken, F.; Compton, R. G.; Electroanalysis 1998, 10,26

79. Blythe, A. N.; Akkermans, R. P.; Compton, R. G.; Electroanalysis 2000, $12,16$.

80. Saterlay, A. J.; Foord, J. S.; Compton, R. G.; Analyst 1999, 124, 1791.

81. Goodwin, A.; Lawrence, A. L.; Banks, C. E.; Wantz, F.; Omanovic, D.; Komorski-Lovric, E.; Compton, R. G.; Anal. Chim. Acta 2005, 533, 141.

82. Simm, A. O.; Banks, C. E.; Compton, R. G.; Electroanalysis 2005, 17, 1727.

83. Simm, A. O.; Banks, C. E.; Compton, R. G.; Electroanalysis 2005, 17, 335.
84. Saterlay, A. J.; Marken, F.; Foord, J. S.; Compton, R. G.; Talanta 2000, $53,403$.

85. Hardcastle, J. L.; Murcott, G. G.; Compton, R. G.; Electroanalysis 2000, 12,559 .

86. Agra-Gutierrez, C.; Hardcastle, J. L.; Ball, J. C.; Compton, R. G.; Analyst 1999, 124, 1053

87. Hardcastle, J. L.; Compton, R. G.; Electroanalysis 2002, 14, 753.

88. Agra-Gutierrez, C.; Compton, R. G.; Electroanalysis 1998, 10, 204.

89. Banks, C. E.; Kruusma, J.; Hyde, M. E.; Salimi, A.; Compton, R. G.; Anal. Bioanal. Chem. 2004, 379, 277.

90. Hardcastle, J. L.; Compton, R. G.; Electroanalysis 2001, 13, 89.

91. Agra-Gutierrez, C.; Compton, R. G.; Electroanalysis 1998, 10, 603.

92. Marken, F.; Rebbitt, T. O.; Booth, J.; Compton, R. G.; Electroanalysis 1997, $9,19$.

93. Davis, J.; Moorcroft, M. J.; Wilkins, S. J.; Compton, R. G.; Cardosi, M. F.; Electroanalysis 2000, 12, 1363.

94. Hardcastle, J. L.; Paterson, C. J.; Compton, R. G.; Electroanalysis 2001, 13,899 .

95. Beckett, E. L.; Lawrence, N. S.; Evans, R. G.; Davis, J.; Compton, R. G.; Talanta 2001, 54, 871 .

96. Akkermans, R. P.; Wu, M.; Bain, C. D.; Fidel-Suárez, M.; Compton, R. G.; Electroanalysis 1998, 10, 613.

97. Akkermans, R. P.; Wu, M.; Compton, R. G.; Electroanalysis 1998, 10, 814.

98. Compton, R. G.; Matysik, F. M.; Electroanalysis 1996, 8, 218.

99. Adewuyi, Y. G.; Appaw, C.; Ind. Eng. Chem. Res. 2002, 41, 4957.

100. Appaw, C.; Adewuyi, Y. G.; J. Hazard. Mater. 2002, 90, 237.

101. Lu, Y.; Weavers, L. K.; Environ. Sci. Technol. 2002, 36, 232.

102. Hua, I.; Hoffmann, M. R.; Environ. Sci. Technol. 1997, 31, 2237.

103. Flint, E. B.; Suslick, K. S.; Science 1991, 253, 1397.

104. Mason, T. J.; Lorimer, J. P.; Sonochemistry: Theory, Applications and Uses of Ultrasound in Chemistry, Halsted Press (Wiley): Chichester, 1998.

105. Mason, T. J.; Lorimer, J. P.; Applied Sonochemistry, Wiley VCH: Weinheim, 2002.

106. Hart, E.; Fischer, C.; Henglein, A.; Radiat. Phys. Chem. 1990, 36, 511.

107. Misik, V.; Miyoshi, N.; Riesz, P.; J. Phys. Chem. 1995, 99, 3605.

108. Hart, E. J.; Henglein, A.; J. Phys. Chem. 1985, 89, 4342.

109. Wu, J. M.; Huang, H. S.; Livengood, C. D.; Environm. Prog. 1992, 11, 195.

110. Riesz, P.; Berdahl, D.; Christman, C. L.; Environ. Health Persp. 1985, 64, 233.

111. Henglein, A.; Ultrasonics 1987, 25, 6.

112. Abdelsalam, M. E.; Birkin, P. R.; Phys. Chem. Chem. Phys. 2002, 4, 5340.

113. Foord, J. S.; Holt, K. B.; Compton, R. G.; Marken, F.; Kim, D.; Diamond Relat. Mater. 2001, 10, 662.

114. Holt, K. B.; Forryan, C.; Compton, R. G.; Foord, J. S.; Marken, F.; New J. Chem. 2003, 27, 698.

115. Macounova, K.; Klima, J.; Bernard, C.; Degrand, C.; J. Electroanal. Chem. 1998, 457, 141.

116. Lima Leite, R. H.; Cognet, P.; Wilhelm, A. M.; Delmas, H.; Chem. Eng. Sci. 2002, 57, 767.

117. Lorimer, J. P.; Mason, T. J.; Plattes, M.; Phull, S. S.; Ultrason. Sonochem. 2000, 7, 237.

118. Abramov, V. O.; Abramov, O. V.; Gekhman, A. E.; Kuznetsov, V. M.; Price, G. J.; Ultrason. Sonochem. 2006, 13, 303.

119. Yasman, Y.; Bulatov, V.; Gridin, V. V.; Agur, S.; Galil, N.; Armon, R.; Schechter, I.; Ultrason. Sonochem. 2004, 11, 365.

120. Ionita, M. I.; Ene, N. N.; Vanatoru, M.; Roum. Chim. 2001, 46, 75.

121. Pollet, B. G.; Lorimer, J. P.; Hihn, J. Y.; Phull, S. S.; Mason, T. J.; Walton, D. J.; Ultrason. Sonochem. 2002, 9, 267.

122. Banks, C. E.; Lawrence, N. S.; Compton, R. G.; Electroanalysis 2003, 15, 243. 